\title{
Techno-Economic Modelling of Micro-Hydropower Mini-Grids in Nepal to Improve Financial Sustainability and Enable Electric Cooking
}

\author{
William Clements ${ }^{1}, * \mathbb{D}$, Surendra Pandit ${ }^{2}$, Prashanna Bajracharya ${ }^{3}$, Joe Butchers ${ }^{1}$, Sam Williamson ${ }^{1}$, \\ Biraj Gautam ${ }^{3}$ and Paul Harper ${ }^{4}$
}

check for

updates

Citation: Clements, W.; Pandit, S.; Bajracharya, P.; Butchers, J.;

Williamson, S.; Gautam, B.; Harper, P.

Techno-Economic Modelling of

Micro-Hydropower Mini-Grids in

Nepal to Improve Financial

Sustainability and Enable Electric

Cooking. Energies 2021, 14, 4232.

https://doi.org/10.3390/en14144232

Academic Editors: Simon Batchelor and Ed Brown

Received: 25 May 2021

Accepted: 9 July 2021

Published: 13 July 2021

Publisher's Note: MDPI stays neutral with regard to jurisdictional claims in published maps and institutional affiliations.

Copyright: (c) 2021 by the authors. Licensee MDPI, Basel, Switzerland. This article is an open access article distributed under the terms and conditions of the Creative Commons Attribution (CC BY) license (https:/ / creativecommons.org/licenses/by/ $4.0 /$ )
1 Electrical Energy Management Group, Faculty of Engineering, University of Bristol, Bristol BS8 1TR, UK; joe.butchers@bristol.ac.uk (J.B.); Sam.Williamson@bristol.ac.uk (S.W.)

2 Kathmandu Alternative Power and Energy Group (KAPEG), Kathmandu 44600, Nepal; s.pandit@kapeg.com.np

3 People Energy and Environment Development Association (PEEDA), Kathmandu 44600, Nepal; prashanna@peeda.net (P.B.); biraj@peeda.net (B.G.)

4 Department of Civil Engineering, Faculty of Engineering, University of Bristol, Bristol BS8 1TR, UK; paul.harper@bristol.ac.uk

* Correspondence: will.clements@bristol.ac.uk

\begin{abstract}
In rural Nepal, micro-hydropower plant mini-grids provide renewable electricity to thousands of communities but the plants often have poor financial sustainability. Widespread uptake of electric cooking in such communities is currently not feasible due to high peak loads and limited capacity. In this paper, we develop a Remote-Areas Multi-Energy Systems Load Profiles (RAMP)-based stochastic techno-economic model for evaluating the economic viability of off-grid communities and improving their financial sustainability by introducing new appliances, productive end uses, and demand-side management measures. The model can be used to understand community electricity demand, assess economic status, determine equitable and profitable tariff structures, and plan new connections including electric cooking promotion or new industrial machines. Detailed electric cooking load modelling functionality was developed to represent Nepali cooking practices, scalable to approximate widespread uptake of electric cooking, and adaptable to other cookers and contexts. The model showed that a payment structure based on electricity consumption rather than a flat tariff could increase the income of a case study community in Eastern Nepal by $400 \%$, although increased monthly payments for certain households from NPR 110 (USD 0.93) to NPR 500-1100 (USD 4.22-9.29) could present difficulty. However, households could reduce their electricity consumption and a more equitable tariff structure could be chosen while preserving plant profitability. The number of industrial machines such as mills could be doubled and up to 40 households provided with electric cookers if demand-side management measures were introduced.
\end{abstract}

Keywords: micro-hydropower; mini-grid; Nepal; techno-economic model; electric cooking; demandside management

\section{Introduction}

Sustainable Development Goal (SDG) 7 is a call for affordable, reliable, sustainable, and modern energy for all [1]. There are around 3300 micro-hydropower plant (MHP) mini-grids in rural Nepal, each providing renewable electricity to hundreds or thousands of beneficiaries [2]. However, this energy provision varies widely in affordability, reliability, and sustainability [3-6], and the use of traditional energy sources such as firewood is prevalent $[7,8]$, resulting in indoor air pollution which accounts for the premature deaths of 22,000 people in Nepal every year [9].

As well as powering households in a community, MHPs provide energy for commercial connections such as shops and mobile phone masts, community services including 
schools and health posts, and industrial end uses such as flour and grain mills, all of which can be referred to as productive end uses (PEUs) [3,10-13]. MHPs are operated at constant power but community electricity demand varies widely, often from a relatively low level at off-peak times to a high level at peak times in the morning and evening $[14,15]$. Consequently, many MHPs suffer from low load factors and a large proportion of generated energy is wasted $[5,16]$. However, high peak loads can approach maximum generation capacity and lead to low voltage events, known as brownouts, and complete system failures, i.e., blackouts $[17,18]$. Low load factors and mini-grid weakness contribute to low financial viability for some MHPs that are unable to generate sufficient income from consumers and PEUs to cover costs and essential maintenance $[3,16,19]$.

Some MHPs have effective management structures and bookkeeping but in many cases there is no record keeping or proper accounting [3,16,20,21]. There is often a lack of understanding on how the addition of new PEUs and appliances would affect the overall electricity demand and generated income. Electric cooking is common in cities in Nepal but less so in rural areas. However, rice cookers and electric kettles are becoming increasingly prevalent, comprising a significant proportion of demand due to their high power, and therefore increasing generated income where consumption is metered [10]. Recent electric cooking trial studies conducted by the authors in rural Nepal used cooking diaries to characterise the Nepali cooking context, collecting detailed information on participants usage of traditional and electric stoves $[14,15,22]$. The studies found that, as people tend to cook at similar times and peak loads are often already high, with only 10 and 15 households cooking with electricity out of around 450 and 1100 households, respectively, the generation capacity was often reached, showing that electric cooking scalability in MHP communities is currently limited. However, the feasibility and benefits of electric cooking to health and quality of life were confirmed [14,15,22]. Demand-side management (DSM) measures can be used to reduce peak loads and enable increased connections of PEUs or appliances such as electric cookers [17,23]. For example, in Myanmar, a community agreement was reached that if the grid voltage dropped below $180 \mathrm{~V}$ consumers would not switch on their cookers [23].

In addition to technical factors, social and cultural influences can reduce plant financial sustainability. MHPs are often community owned and effectively began as social enterprises, fulfilling the basic need of community members for electricity, who were often involved in the construction of the plants [16]. This has led to tariffs being set too low to generate healthy profits, with committees reluctant to increase them for fear of social unrest among consumers $[16,19,24]$. Some community members are reluctant to pay for MHP electricity after giving their time during plant construction [16]. Management issues such as difficulty and inefficiency concerning tariff collection further reduce the proportion of paying consumers $[3,19]$. Many MHPs charge consumers based on electricity meters installed in their homes, but some charge the same flat rate to all households regardless of their electricity usage [3]. Off-grid electricity in Nepal was found to be more price inelastic than its grid counterpart [25], but changes to payment structures could result in consumer behaviour changes [26]. Low tariffs, missed payments, and management issues contribute to low financial sustainability.

Studies surveying multiple MHPs in Nepal have identified a wide range of plant financial viabilities $[3,16]$. PEUs and electric cooking can support the financial viability of MHPs but their introduction requires understanding of the community load profile to ensure technical viability. To understand and evaluate the financial sustainability of MHPs, a realistic model of electricity demand is required. An MHP community is a complex system of consumer behaviours and cultural appliance usage patterns. As explained in [27], many residential load modelling tools have been conceived, employing stochastic approaches to incorporate inherent uncertainties and generate realistic profiles. However, they are usually designed for on-grid contexts in developed countries and reliant on the input of detailed data from activity diaries, detailed time-use surveys, or other available statistical datasets [28-33]. In remote communities such as MHPs in Nepal, detailed appliance usage 
data is often difficult to obtain to a high level of accuracy and demand modelling must be based on surveys and interviews with limited sample sizes that are imprecise and subject to significant uncertainty [27].

ESCoBox is a set of tools including software and hardware designed for off-grid electricity planning and DSM [34]. A decision-support tool uses data on hourly usage of end uses to estimate daily load profiles, while the hardware can limit power for PEUs to certain windows of time according to the model outputs. While very useful for certain contexts, it does not disaggregate demand to household groups or model devices used less than once per day, and it produces outputs at an hourly resolution only. Therefore, it lacks the precision required for a detailed monthly breakdown of energy consumption and income. LoadProGen uses a bottom-up stochastic approach designed for interview and survey data [35]. "Remote-Areas Multi-Energy Systems Load Profiles" (RAMP) builds on this approach by increasing the level of stochasticity and extending its applicability to include loads such as water heating or cooking, by incorporating random variations of power levels and cycling of power [27]. RAMP applies stochasticity to several parameters related to appliance usage such as windows of use, durations, and frequency of use, to capture uncertainties and variations from relatively low detail input data. Its modelling strategy is flexible and customisable, and therefore applicable to a wide range of contexts, and has been employed successfully for a number of projects in [27,36-38]. RAMP and LoadProGen have also been used effectively to model cooking loads in several contexts $[37,39,40]$.

The aim of this paper is to develop a techno-economic model for evaluating and improving the financial sustainability of MHPs. Using RAMP, a realistic model of the electricity demand of an MHP community including electric cooking is developed, approximating the load breakdown of households and PEUs, to estimate their energy consumption, resulting payments, and the total income generated. We use the model to explore how tariffs can be set to balance the needs of the people and the plant, ensuring sufficient income while remaining fair and inclusive for consumers. We also aim to understand how the introduction of additional PEUs, appliances such as electric cookers, and the use of DSM measures, can improve MHP economic status while preserving technical viability. The model can approximate load profiles of an increased number of households that are cooking with electricity to understand how increased uptake of electric cooking could be enabled in a mini-grid with constrained capacity. Overall, the model is used to show that MHP economic viability can be improved by payment structures based on electricity consumption and the introduction of additional PEUs, appliances such as electric cookers, and DSM measures. This is the first study to develop a detailed techno-economic model of a Nepali MHP community.

The remainder of this paper is structured as follows. In Section 2, we provide details of the MHP community case study which the work was focussed on; in Section 3 Methodology, we outline the methodology of the research; in Section 4, we explain the data collection activities undertaken and key results used to inform the model development; in Section 5, we describe the techno-economic model development and validation and explain how RAMP was used and adapted to create a realistic model of the community electricity demand, including stochastic modelling of cooking loads, validation against measured data, and plant economics; in Section 6, we present the results of the evaluation of different payment structures in the case study community, and the technical and economic effects of additional end uses, DSM measures, and increased uptake of electric cooking; in Section 7, we discuss the analyses of the results and outline model limitations; and in Section 8 we provide conclusions and future work.

\section{Case Study}

A rural MHP community called Salyan within the rural municipality Necha-Salyan in the Solukhumbu district, Eastern Nepal, was chosen as the case study. Figure 1 presents the location of the rural municipality and Figure 2 is a photograph of the MHP powerhouse. Table 1 presents key information on the community. There are 1093 households (HHs) 
in the village and 17 types of PEUs including business (BEUs), community (CEUs), and industrial end uses (IEUs). The MHP is community owned and currently most beneficiaries pay a flat rate of NPR 110 per month for electricity, which is approximately USD 0.93 as of June 2021, while some IEU operators are charged according to their electricity consumption. The community was the focus of the most recent cooking diary study conducted by the authors and is one of two communities which are part of a current project focussed on trialling electric pressure cookers, both of which were funded by Modern Energy Cooking Services (MECS) [22,41].

In an MHP, pressurized water is converted into mechanical power shaft power by a turbine, which drives an electrical generator. Three-phase power is generated and distributed to HHs in the community, with each phase roughly balanced so the loads are shared equally across all phases. MHP systems typically operate at a constant output power. An electronic load controller (ELC) is used to balance the load on the system through the use of a dump load; as the consumer load decreases, the ELC diverts more power to the dump load, or vice versa [42]. The ELC maintains the mini-grid frequency and voltage within desired ranges, in this case around $50 \mathrm{~Hz}, 230 \mathrm{~V}$.

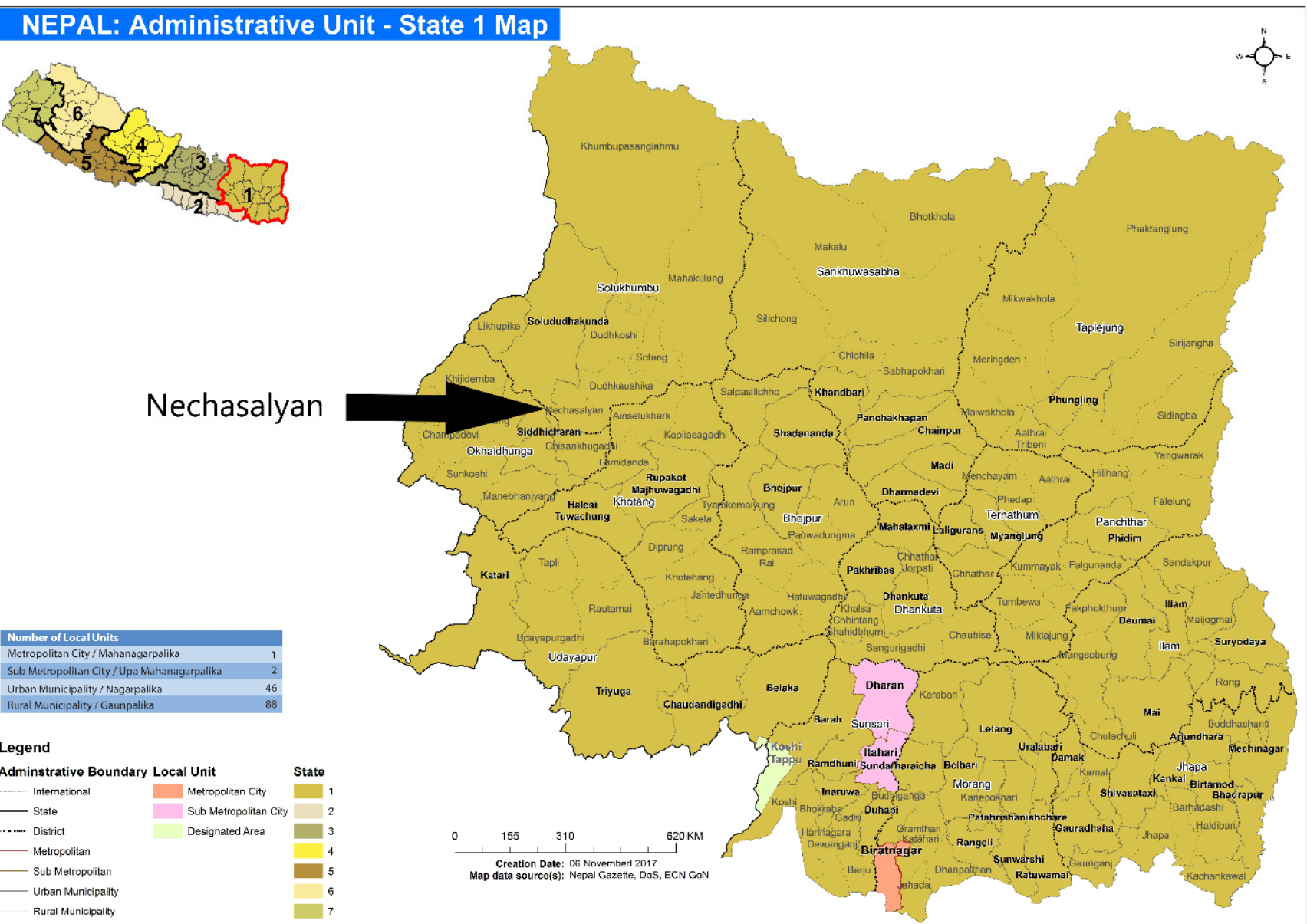

Figure 1. A map of Province 1, Eastern Nepal, showing the location of the case study community [43]. 


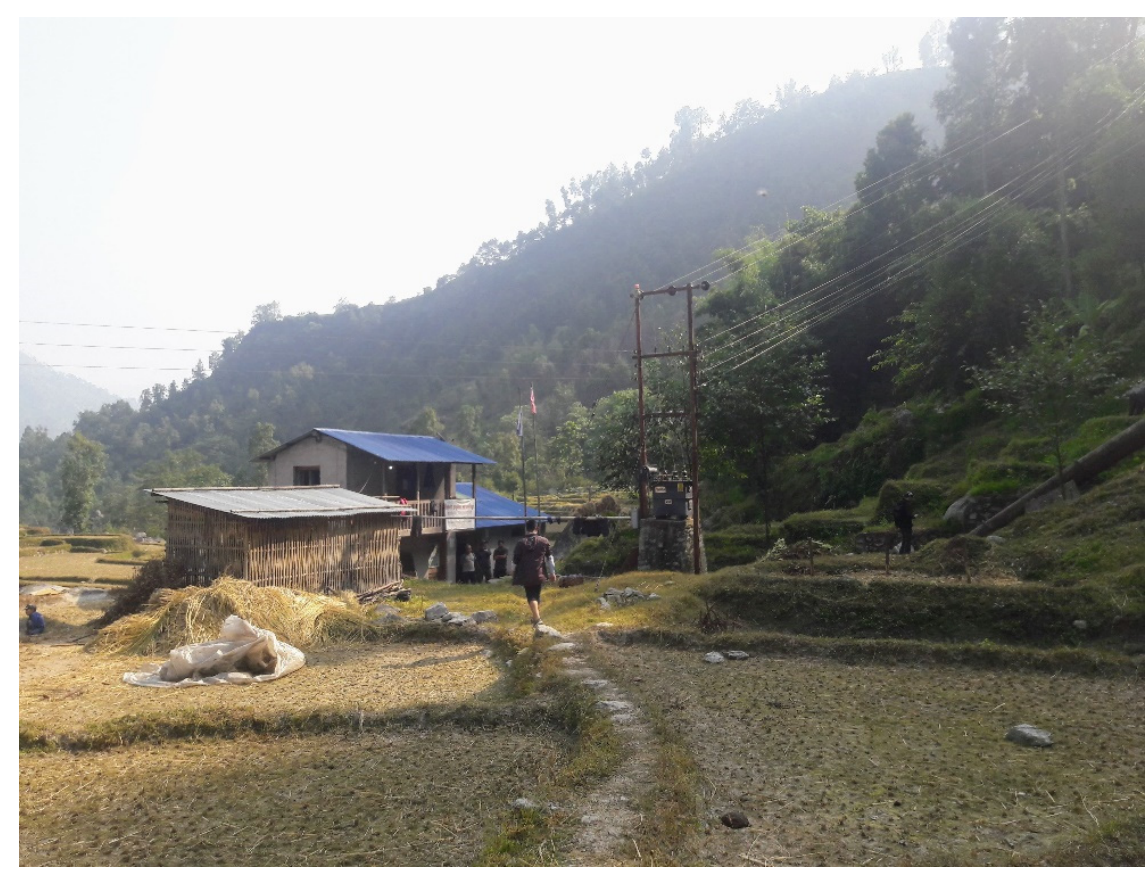

Figure 2. The MHP powerhouse in Salyan, the case study community.

Table 1. Case study community key information.

\begin{tabular}{lll}
\hline Number of households & 1093 \\
\hline Types of productive end uses & 17 \\
\hline Tariff system & & NPR 110 (USD 0.93), flat rate \\
\hline Generation capacity $(\mathrm{kW})$ & Type & 100 \\
\cline { 2 - 3 } & Gross head (metres) & Crossflow \\
\cline { 2 - 3 } Turbine & Design flow (litres per second) & 380 \\
\cline { 2 - 3 } & Speed (RPM) & 850 \\
\hline
\end{tabular}

\section{Methodology}

In this paper, a techno-economic model is developed to calculate the overall plant income, profit, the income breakdown across consumers, and generate daily and average load profiles across a typical month. Figure 3 presents a flow chart of the methodology of the study. The model requires a breakdown of user energy consumption and realistic electricity demand profiles. RAMP is used to generate load profiles and augmented to enable realistic modelling of electric cooking loads, incorporating extended cycle functionality to represent typical practices of cooking dishes sequentially at varying power levels. The RAMP model required data on the electricity demand of $\mathrm{HH}$ and PEUs, recent powerhouse load profiles for model validation, and cooking diary data for specification and validation of RAMP electric cooking modelling. Together with this demand data, data were also required on plant costs, profit allocations, the proportion of paying consumers, and energy lost due to brownouts and blackouts. According to MHP bylaws, $15 \%$ of total revenue should be allocated to repairs and maintenance, $25 \%$ of total profit should be allocated to a backup fund, and $25 \%$ of total profit should be allocated to a community development fund [16]. The collected data, information, and model outputs are then combined to understand the impact of different tariff structures and end uses on the techno-economic viability of the MHP. 
Demand data:

Electricity demand of HHs and PEUs,

powerhouse load profiles, cooking diaries
System data:

Costs, fund allocations, \% paying consumers, \% energy lost

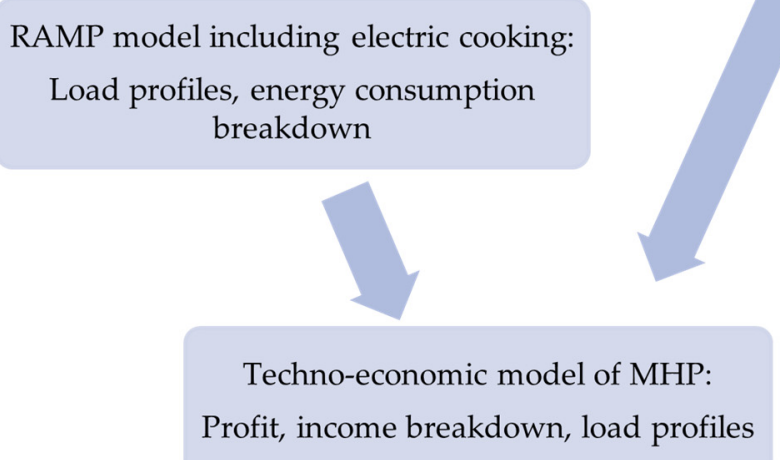

Figure 3. Flow chart of the study methodology.

\section{Data Collection}

Data was collected from several sources between December 2020 and March 2021 in order to create and validate the RAMP model, understand the current and planned status of the MHP, and gain insight into consumer attitudes toward the plant and their cultural cooking context. A survey was conducted with the MHP secretary on the plant status and end uses, contributing both system and demand data. Key insights included that the monthly plant income was low at around NPR 50,000 (USD 420) due to the flat rate and a large proportion of consumers not paying their bills. Therefore, the plant was sometimes unable to cover the costs of repairs, maintenance, and salaries of its three employees, and recently required financial assistance from the local government for maintenance works. To improve the situation, the MHP committee plans to implement a new payment structure based on energy consumption and the process of making the transition to the system is underway. The new system would include tariff collection by staff members on the assumption that additional staff costs would be recuperated by increased revenue due to increased payments for some consumers and an increased percentage of consumers paying regularly.

The survey also asked for information on the PEUs, their appliance ownership, and appliance power ratings, where possible, to generate electricity demand data. For IEUs such as mills, more detailed usage data were collected because high-power machines have a large effect on the electricity demand profile, especially if several are in use at the same time. The survey data were complemented by a member of the research team visiting the PEUs to extend understanding of appliance ownership and usage. Table 2 shows the proposed tariff structure with end uses grouped by connection type and their numerosity in brackets, for example, there are two banks, both of which have a 16 A connection. Higher current connections are charged more for electricity. An important insight is that the operators of the three phase rice mills have an agreement not to operate their mills after 5 p.m. to reduce the evening peak demand. The results of all surveys, presented as inputs to RAMP, are available in a publicly accessible data repository. 
Table 2. Proposed payment structure by meter connection and breakdown of end uses.

\begin{tabular}{lllll}
\hline Meter & 3A/6 A & $10 \mathrm{~A}$ & $16 \mathrm{~A}$ & $32 \mathrm{~A}$ \\
\hline Minimum unit (kWh) & 18 & 32 & 40 & 50 \\
\hline $\begin{array}{l}\text { Minimum unit charge } \\
\text { (NPR) }\end{array}$ & 110 (USD 0.93) & 250 (USD 2.11) & 300 (USD 2.53) & 350 (USD 2.95) \\
\hline $\begin{array}{l}\text { Per unit charge above } \\
\text { minimum (NPR) }\end{array}$ & 7 (USD 0.06) & 8 (USD 0.07) & 8 & 8 \\
\hline End uses & $\begin{array}{l}\text { Households (99\% of 1093) } \\
\text { Shops (15) }\end{array}$ & $\begin{array}{l}\text { Households (1\% of 1093) } \\
\text { Schools } \\
\text { (Primary) (9) } \\
\text { MHP office (1) } \\
\text { Government offices (2) }\end{array}$ & $\begin{array}{l}\text { Schools } \\
\text { (Higher (3), Secondary (2) } \\
\text { and Campus (2)) } \\
\text { Cold storage (1) } \\
\text { Health-post (1) } \\
\text { Banks (2) }\end{array}$ & $\begin{array}{l}\text { Crusher (1) } \\
\text { Telecoms tower (1) }\end{array}$ \\
$\begin{array}{l}\text { Police station (1) } \\
\text { Poultry farms (4) } \\
\text { Single phase mills (3) }\end{array}$ & & & \\
\hline
\end{tabular}

The number of HHs in the community (1093) implies that they are likely to dominate the electricity demand. Therefore, it was necessary to capture information on device ownership, power ratings, frequency of usage, usage windows, and durations from a sample of HHs. Alongside the current electric cooking project, a HH survey was conducted in $30 \mathrm{HHs}$, the largest sample feasible given project timescales. The survey collected data to a level of detail appropriate considering participant workload and inherent uncertainties, for example, asking for periods of the day during which participants typically used devices. Figure 4 presents percentage ownership of domestic end uses among the sample.

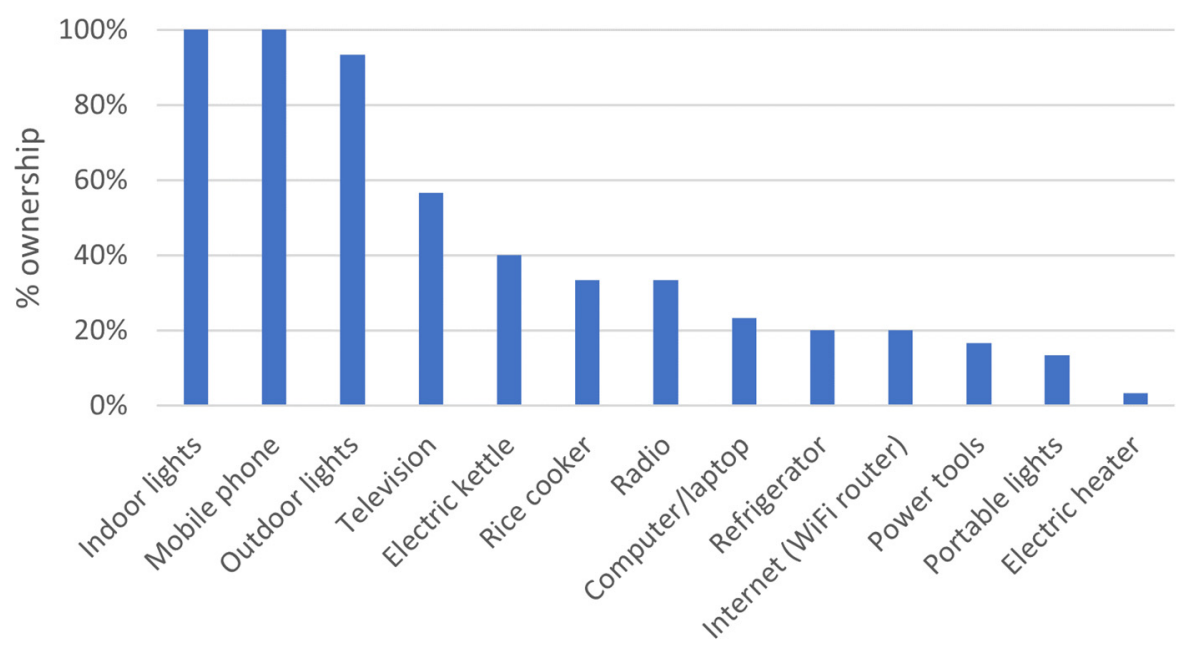

Domestic end uses

Figure 4. Percentage ownership of household devices in the thirty-household sample.

Cooking diary data from the studies in the community were used to model cooking loads and for RAMP parameters for electric cooking appliances including rice cookers and electric kettles [22]. Powerhouse electrical data from these studies contributed system and demand data, including the frequency of brownouts and blackouts, the spare energy capacity at peak times, the load factor, and demand profiles for comparison to RAMP model outputs. Figure 5 shows examples of typical load and voltage profiles from December 2020. The load factor is relatively high for an MHP, with the base load around $40 \mathrm{~kW}$ in off-peak times [16]. As found in [22], there is little spare power at peak times, short blackouts are frequent, and brownouts are common during peak times, with voltage dropping to around $200 \mathrm{~V}$. 


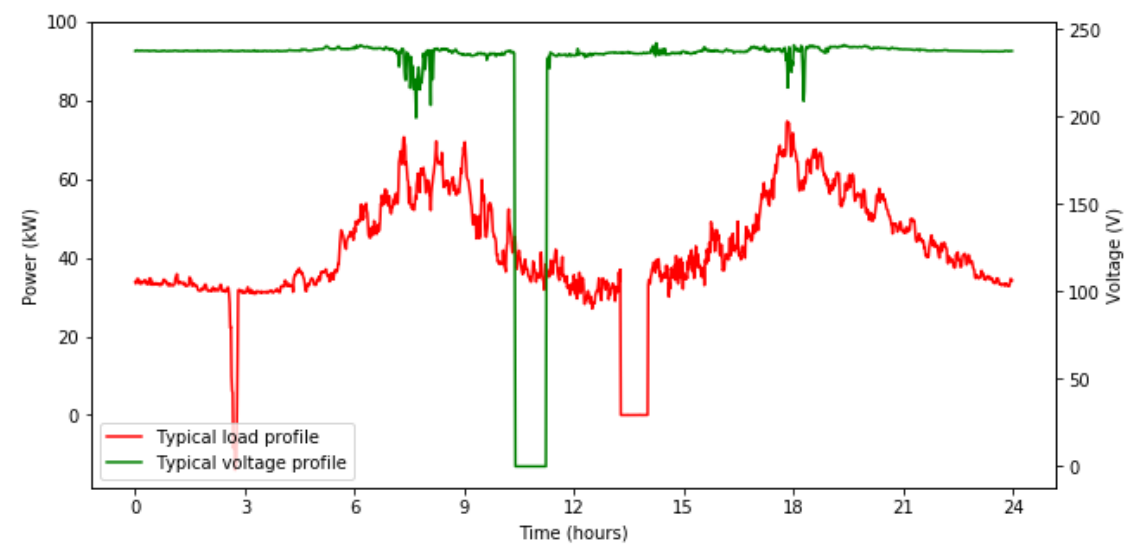

Figure 5. Typical load and voltage profiles measured in the MHP powerhouse in December 2020.

\section{Techno-Economic Model Development and Validation}

The RAMP inputs and code files used in this study are available in a publicly accessible repository, with functionality fully explained in [27]. RAMP version 0.2.1-pre was used and augmented for the study. The latest version of RAMP is freely accessible as "RemoteAreas Multi-Energy Systems Load Profiles" (RAMP) from the GitHub repository: https: / / github.com/SESAM-Polimi/RAMP, accessed on 12 July 2021. Minor adaptations to the code were made to adjust the probabilities of coincident switch-on of multiple numerosity appliances, such as lights and mobile phones, in on- and off-peak time windows. In both cases, the likelihood of the coincident switch-on of all instances of the appliance was increased.

\subsection{PEU and Domestic Load Modelling}

Table 2 presents the end uses, which correspond to user types in RAMP, and their numerosity. For each, user type appliances were specified according to their numerosity, power rating, total daily usage, minimum usage per switch-on, windows of usage, weekly frequency of use where applicable, and duty cycles of varying power levels where required. These parameters were mostly specified from the collected survey data, and alternative sources used for power ratings where survey data were lacking using references [34,37,44], including a previous field study conducted by PEEDA in rural Nepal [44]. Randomness factors which variate durations, windows, duty cycles, and powers according to uniform distributions were specified according to survey usage data, sensitivity analyses, and authors' experiences. For each model run, RAMP creates and aggregates independent stochastic load profiles for every user within each user type, with multiple runs generating a series of daily load profiles. For the schools, offices, banks, and police station, weekend profiles were not created. In Salyan, Friday is a half day for some community activities while Saturday is a holiday, therefore RAMP omitting two days for these end uses is a conservative measure but has little impact as HHs, BEUs, and IEUs dominate demand.

To understand and model the variation in $\mathrm{HH}$ appliance ownership and usage, $\mathrm{HH}$ user types were created based on $\mathrm{HH}$ survey results, representing degrees of income level within the community. Appliance numerosity and usage durations were varied around the mean across the groups, increasing with income level. Table 3 presents the HH types, percentage of the total $1093 \mathrm{HHs}$, and appliances owned, including the HHs with electric cookers which were part of the previous cooking diary study [22]. Type 5 is a small number of HHs owning all surveyed appliances. In reality, appliance ownership varies widely across the community, with, for example, some HHs owning rice cookers but not electric kettles and vice versa, but the user types created approximate clusters of HHs sufficiently for differentiating consumers. 
Table 3. Household type groupings, percentage of households in the community, and appliances owned.

\begin{tabular}{lll}
\hline Household Type & \% of (Total Number) & Appliances Owned \\
\hline 1 & $40(437)$ & Indoor and outdoor lights, mobile phones \\
\hline $29(318)$ & Indoor and outdoor lights, mobile phones, TV \\
\hline 3 & $15(164)$ & $\begin{array}{l}\text { Indoor and outdoor lights, mobile phones, TV, radio, rice cooker, } \\
\text { electric kettle }\end{array}$ \\
\hline 5 & $14(154)$ & $\begin{array}{l}\text { Indoor and outdoor lights, mobile phones, TV, radio, rice cooker, } \\
\text { electric kettle, laptop, router, refrigerator, torch }\end{array}$ \\
\hline Induction & $1(10)$ & $\begin{array}{l}\text { Indoor and outdoor lights, mobile phones, TV, radio, rice cooker, } \\
\text { electric kettle, laptop, router, refrigerator, torch, heater, power tools }\end{array}$ \\
\hline Induction + rice & HH type 2 plus induction cooker \\
\hline
\end{tabular}

Frequency of use was specified for most appliances and varied across $\mathrm{HH}$ types. For example, Type 4 was modelled to use their rice cookers and electric kettles once every two days, to capture frequent but varying usage within the user type, whereas the frequency was lower at once every five days for Type 3 to represent occasional usage. Varying the frequency of use also represents days where HHs are away from home and instances where brownouts might lead to reluctance to use electrical appliances.

\subsection{Electric Cooking Load Modelling}

During the previous cooking diary study, 15 HHs were provided with induction cookers, with four HHs also provided with rice cookers [22]. RAMP was augmented with additional code functionality to enable realistic modelling of Nepali cooking loads using data from the previous cooking diary study on durations, time windows, power levels, and dish frequency. The main addition was an extension of the cycling functionality, enabling cycles of up to six parts with different durations and power levels. In Salyan, the meal that is most frequently cooked consists of lentil stew, rice, and vegetables, known locally as dal bhat tarkari. According to diary data, some HHs cooked two or three dishes sequentially on the induction cookers, and it was common to start the cooker at its maximum power of $1 \mathrm{~kW}$ and subsequently reduce it to a lower level while cooking each dish.

Table 4 presents the modelling specification for typical daily cooking practices in Salyan, including cooking cycles, for typical HH sizes of 4-5 people, as found in the previous cooking diary study. Time windows are 7-10 a.m., 12-4 p.m., and 5-8 p.m. for breakfast, lunch, and dinner, respectively, while water heating events representing tea or drinking water are allowed to occur a varying number of times across the day. Dal and rice are generally cooked in traditional cooking pots or stovetop pressure cookers, while vegetables, meat, noodles, and potatoes are mainly fried in a saucepan called a kadhai [15]. All dishes can be represented as high power $(\mathrm{HP})(1 \mathrm{~kW})$ for an initial ten-minute preheat period followed by a reduced heat or simmering period at medium power (MP) $(700 \mathrm{~W})$. The induction cooker power is allowed to vary randomly by up to $20 \%$ around the specified level, accounting for different power level selections and cookers with higher maximum power than $1 \mathrm{~kW}$, as cooking diary studies have revealed that participants adjust the power to varying levels during cooking $[15,22]$. 
Table 4. RAMP electric cooking load modelling specification.

\begin{tabular}{|c|c|c|c|c|}
\hline Meal (Frequency (\%)) & No. Dishes & Dishes & Frequency $(\%)$ & Cooking Cycle/Typology \\
\hline \multirow[t]{3}{*}{ Breakfast $1(90 \%)$} & 3 & Dal, rice, vegetables & 30 & $\begin{array}{l}\text { Dal: HP } 10 \mathrm{~min} \text { (frying/boiling), MP } 15 \mathrm{~min} \\
\text { (simmering) } \\
\text { Rice: HP } 10 \mathrm{~min} \text { (boiling), MP } 15 \mathrm{~min} \\
\text { (simmering) } \\
\text { Vegetables: HP } 10 \mathrm{~min} \text { (frying), MP } 20 \mathrm{~min} \\
\text { (lower heat) }\end{array}$ \\
\hline & 2 & Rice, vegetables & 50 & See above \\
\hline & 1 & Dal or rice & 20 & See above \\
\hline \multirow[t]{2}{*}{ Breakfast $2(10 \%)$} & 2 & Meat, rice & 70 & $\begin{array}{l}\text { Meat: HP } 10 \text { min (frying), MP } 25 \text { min } \\
\text { (lower heat) }\end{array}$ \\
\hline & 1 & Meat or rice & 30 & See above \\
\hline Lunch $1(50 \%)$ & 1 & Noodles & 50 & HP 10 min (boiling), MP 10 min (simmering) \\
\hline Lunch $2(50 \%)$ & 1 & Potatoes & 50 & HP 10 min (frying), MP 15 min (lower heat) \\
\hline Dinner $1(80 \%)$ & & & & Same as Breakfast 1 except frequency $80 \%$ \\
\hline Dinner $2(20 \%)$ & & & & Same as Breakfast 2 except frequency $20 \%$ \\
\hline
\end{tabular}

Another major addition to RAMP was the incorporation of "meal selector" parameters, similar to the user_pref factor present in RAMP that allows different meal options to be randomly selected with certain probabilities, which correspond to the frequencies in Table 4, chosen according to cooking diary data. Breakfast and dinner modelling included two layers of selectors, firstly, between different meals, and then for different numbers of dishes cooked on electric cookers. Fuel stacking is common, with participants cooking with different fuels to save time or out of preference for cooking experience or taste. In the previous study, fuel stacking meant that $70-80 \%$ of dishes were cooked with electricity [22]. Therefore, the second selector chooses options where one, two, or three dishes are cooked with electricity. Meat, rice meals could also represent chapati, vegetables meals which are also a feature of cooking practices in Salyan. Single dish events could represent a wide range of dishes. For the lunchtime meal, the cooking diaries revealed that noodles or fried potatoes are the two most common meals, and therefore only one selector was required. Fuel stacking was also accounted for by setting the overall appliance frequency of use at $90 \%$ to account for meals where HHs cooked entirely using wood or liquid petroleum gas (LPG), or did not cook at home.

HHs with rice cookers were modelled in the same way as those without, except with the addition of a separate appliance representing rice cooked in the rice cooker, enabling the possibility of concurrent induction and rice cooker usage, as was often found in cooking diary data. A limitation of this was the difficulty ensuring that induction and rice cooker events happen at close to the same time, since the independence of each appliance meant that RAMP could schedule them at opposite ends of a time window. Figure 6 presents an example of an $\mathrm{HH}$ electric cooking load profile: an early water heating event, a six-part cycle for breakfast including power level variation, a single dish lunch and short water heating event, and finally an evening water heating event, with dinner cooked on an alternative stove or had elsewhere. Although not perfectly realistic as cookers have discrete power levels, the random power variation is more representative of consumer behaviour and differences between cookers than fixed power levels. Two further changes were made to RAMP for modelling electric cooking, i.e., preventing a cycle repeating after duration randomisation, and ensuring sufficient time remaining in a time window for a full cooking cycle to be completed. 


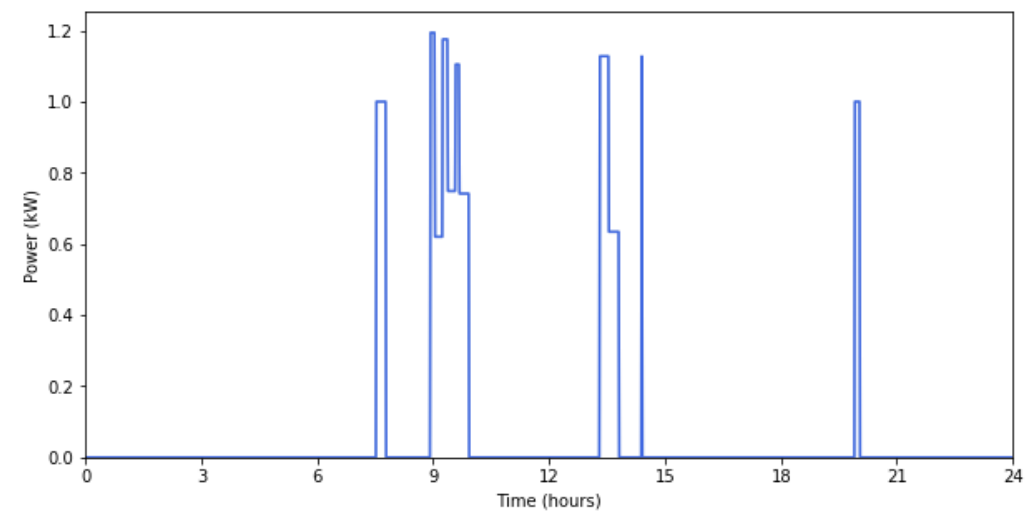

Figure 6. Example of RAMP output electric cooking load profile for one household with an induction cooker.

The cooking load modelling was validated by comparing outputs to cooking diary data load profiles generated from energy meter readings and event durations during the diary study. The average power values during cooking events were aggregated across the $\mathrm{HHs}$, and then averaged to create an approximate daily load profile. Figure 7 shows the comparison of the RAMP and diary curves for $15 \mathrm{HHs}$, showing reasonable agreement between the profiles. The maximum peaks across the 14-day period were 11.3 and $11.2 \mathrm{~kW}$ for the RAMP and diary profiles, respectively, showing that similar variability was obtained with each method. The adherence of the generated profile to the measured data is also evaluated by means of the normalised root-mean-squared error (NRMSE) (Equation (1)):

$$
\text { NRMSE }=\frac{\sqrt{\frac{\sum_{x}^{N_{t}}\left(P_{R A M P}(x)-P_{\text {diary }}(x)\right)^{2}}{N_{t}}}}{P_{\text {diary,average }}}[\%]
$$

where $P_{R A M P}(x)[\mathrm{kW}]$ is the RAMP profile value at each timestep $x, P_{\text {diary }}(x)[\mathrm{kW}]$ is that of the diary profile, $N_{t}$ is the total number of timesteps (1440 for one minute resolution), and $P_{\text {diary,average }}[\mathrm{kW}]$ is the mean of the diary profile. The NRMSE is $18.3 \%$, indicating reasonably high adherence. Part of the difference between the profiles occurs in the lunchtime period. During the diary study, many HHs rarely ate their lunchtime meal at home due to work commitments, giving rise to a low afternoon electric cooking load. The RAMP cooking model accounts for an increased level of lunchtime electric cooking as other HH members could use the cooker and more meals might be cooked at home during holiday periods.

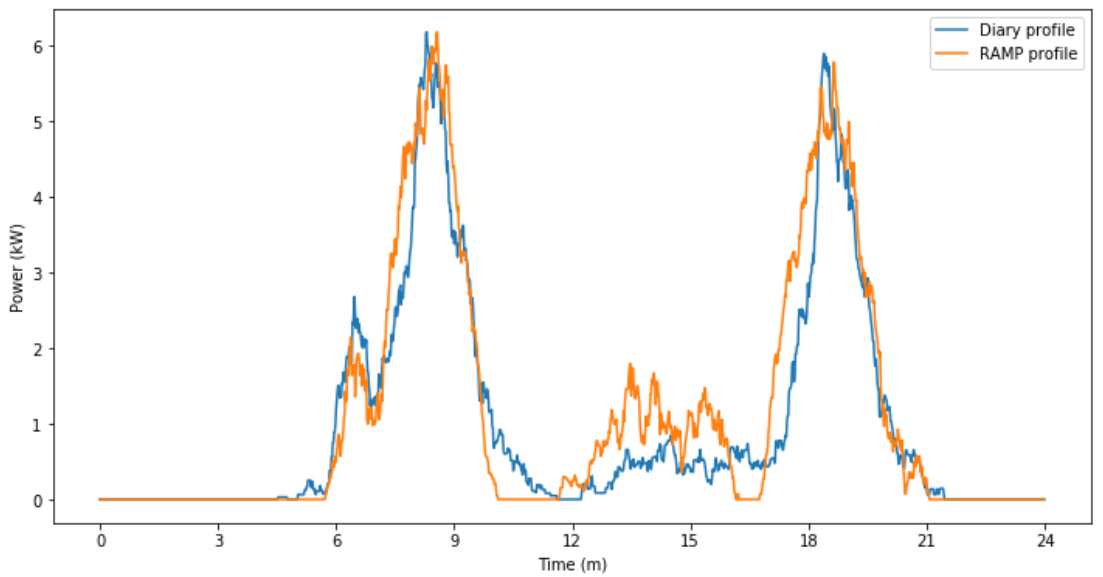

Figure 7. Comparison of average RAMP electric cooking load profile and cooking diary data profile for 15 households. 


\subsection{Community Techno-Economic Model}

After validating the electric cooking model, the community RAMP model was updated with 10 and 2 of each electric cooking $\mathrm{HH}$ rather than 11 and 4 as recent surveys revealed that some cookers had broken down. The frequency of use was also reduced from $90 \%$ to $70 \%$ to represent more realistic fuel stacking than during the original cooking trials, when HHs were encouraged to use the cookers as often as possible. Load profiles from the previous cooking diary study were used to validate the community RAMP model [22]. Figure 8 presents a comparison of thirty-day RAMP outputs and a diary study average load profile over 12 days in late 2019. The red line shows the average RAMP load profile across the thirty days of a typical month, with the background pink cloud depicting the variation in daily profiles. There is reasonable agreement between the average RAMP profile and the measured data, with the NRMSE calculated to be $10.3 \%$ (Equation (1)). Although the morning peak of the RAMP profile is higher at around $80 \mathrm{~kW}$, this is deemed acceptable as the $5 \mathrm{~kW}$ telecoms tower and $2 \mathrm{~kW}$ cold storage facility were connected in early 2021, and the surveys revealed that some HHs are purchasing high-power devices such as rice cookers and electric kettles. The small peak and trough in the first hour of the RAMP profile can be attributed to an idiosyncrasy of RAMP and have very little impact on the modelled energy consumption.

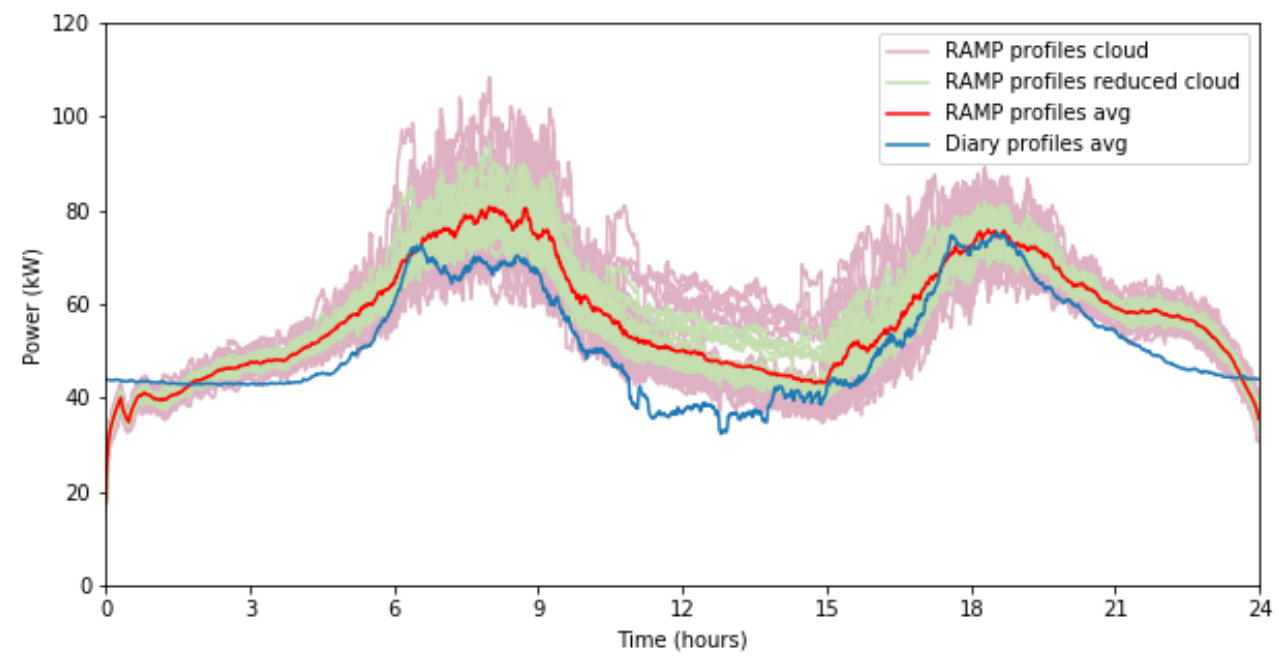

Figure 8. Comparison of community-wide RAMP and diary study average load profiles including daily profiles.

However, the variability of the RAMP daily output profiles is high, from peaks of around $60 \mathrm{~kW}$ to just over $100 \mathrm{~kW}$. It is possible that there are far fewer high-power $\mathrm{HH}$ appliances in the community than assumed, if the sample of thirty HHs is not representative. Reduced voltage during brownouts causes passive loads such as some bulbs, rice cookers, electric kettles, etc., to reduce their power consumption, which could lead to reductions in peak loads not accounted for in RAMP. In addition, the surveys revealed that the MHP operators monitor the state of the mini-grid and request that mill operators switch off their machines when the total load nears capacity, which is difficult to model in RAMP while preserving its stochastic approach. Figure 9 shows the RAMP average output profiles and series broken down into HHs, commercial plus community end uses (ComEUs), and IEUs. HHs and IEUs produce the most variation, with IEU peaks ranging from very low to around $50 \mathrm{~kW}$, showing that operator interventions could have a significant impact on the resulting load. Examination of electrical system data from late 2019 showed that swings of 10-20 kW, rather than up to $40 \mathrm{~kW}$, are common during peak times [22]. Therefore, to obtain profiles with reduced variability, the daily profiles were compared to the average and deviation reduced by $50 \%$ to reduce peak time load ranges to around $20 \mathrm{~kW}$, as shown by the green cloud in Figure 8 . 


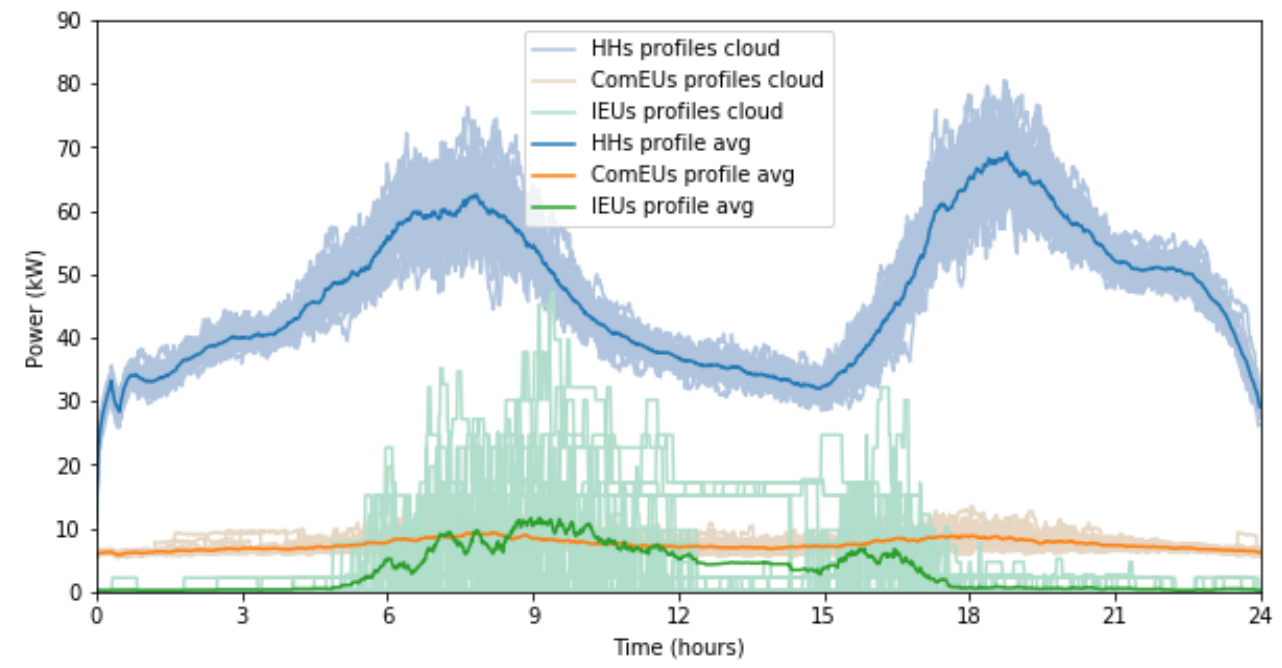

Figure 9. RAMP output profiles split by end use type.

The generated load profiles across a typical month were used to assess the potential economic status of the plant if the new tariff structure was introduced. A month of profiles rather than an entire year was deemed acceptable due to limited data on seasonality and computational resources. The MHP secretary survey revealed that there was little variation in electricity demand across the year. Rather than storing the energy consumption of each individual user, the average consumption was calculated for each user type to save computational resources and focus results. Using the average consumption of a single user in each user type, the tariff system in Table 2 was applied and the resulting average single user income multiplied by number of users in each type to calculate overall user type income and overall plant income.

Two factors are applied during the economic calculations. Firstly, the total energy consumption of each user type is reduced by $10 \%$ to account for brownouts and blackouts, equating to three days of power outages in total across the month, which was deemed a conservative measure for resulting income but possible due to reported occasional shutdowns for maintenance or due to lightning and other external events. Approximately half of the HH survey participants reported frequent electricity supply disturbances. Secondly, the calculated total income for each $\mathrm{HH}$ type excluding the electric cooking HHs is reduced by $20 \%$ to account for a proportion of consumers not paying their bills, both due to a sense of entitlement and exemption due to poverty. The percentage was chosen based on opinions of the MHP secretary and research team, but the true figure is unknown. The final income, calculated for the modelled month and scaled up to a year, is reduced by the fixed costs detailed in Table 5 to calculate overall plant monthly profit. Here, profit refers to monthly running profits rather than also considering initial investment costs. NPR 10,000 (USD 84) was reported to be the likely expenditure on meter readers who would be paid per $\mathrm{HH}$ visited. There is a plan to hire field staff to attend to issues such as distribution line disturbances.

Table 5. Breakdown of plant costs.

\begin{tabular}{ll}
\hline Cost & Amount per Month (NPR) \\
\hline Operator salary (2) & 20,000 (USD 169) \\
Admin staff salary & 10,000 (USD 84) \\
Meter readers payment & 10,000 (USD 84) \\
Field staff salary (2) & 12,500 (USD 105) \\
Maintenance budget & $15 \%$ of total income \\
\hline
\end{tabular}




\section{Results \\ 6.1. Economic Viability}

The monthly revenue of the MHP in Salyan with the flat rate tariff system is only around NPR 50,000 (USD 420). The techno-economic model was used to evaluate the potential economic status of the plant if the transition to the proposed payment structure detailed in Table 2 was completed while consumer behaviour remains as reported in the surveys, Scenario P1. A predicted usage scenario was also created, Scenario P2, in which it was imagined that, after a period of time under the new system, some HHs may reduce their electricity consumption to lower their increased bills. The scenario includes reducing lights, TV, and radio usage per day and, for HH Types 4 and 5, reducing the frequency of rice cooker and electric kettle usage. The scenario was created according to the authors' opinions and experiences of field work in the case study community. The key results are presented in Table 6. The baseline scenario, B, is included, for which the technical parameters are the same as P1, while the monthly profit is currently zero or less as the plant is struggling to cover costs. For each scenario, similar results were obtained over multiple model simulations.

Table 6. Key model results of proposed scenario P1, with current usage patterns, and predicted usage scenario P2.

\begin{tabular}{|c|c|c|c|c|c|c|c|c|}
\hline Scenario & $\begin{array}{l}\text { Energy } \\
(\mathbf{k W h})\end{array}$ & $\begin{array}{l}\text { Income } \\
\text { (NPR) }\end{array}$ & $\begin{array}{l}\text { Costs } \\
\text { (NPR) }\end{array}$ & $\begin{array}{l}\text { Profit } \\
\text { (NPR) }\end{array}$ & $\begin{array}{l}\text { Peak Load } \\
\text { Mean }(k W)\end{array}$ & $\begin{array}{l}\text { Peak Load across } \\
\text { Month (kW) }\end{array}$ & $\begin{array}{l}\text { Peak Load Reduced } \\
\text { Variability }(\mathbf{k W})\end{array}$ & $\begin{array}{c}\text { Average } \\
\text { Load } \\
\text { Factor }(\%)\end{array}$ \\
\hline B & 37,000 & 50,000 & & & 80.7 & 108.4 & 94.6 & 60.9 \\
\hline P1 & 37,000 & 247,000 & 122,000 & 124,900 & 80.7 & 108.4 & 94.6 & 60.9 \\
\hline P2 & 28,300 & 212,100 & 116,800 & 95,300 & 73.2 & 97.9 & 84.4 & 50.9 \\
\hline
\end{tabular}

The model returns a dramatic increase in monthly income from NPR 50,000 (USD 420) to around NPR 250,000 (USD 2110), showing that, even if $20 \%$ of consumers do not pay, the new payment structure could significantly increase the financial sustainability of the plant, generating monthly profits of around NPR 120,000 (USD 1010). Even after 50\% of this remaining profit is allocated to backup and community development funds, NPR 60,000 (USD 510) would remain, and any funds not required for repairs and maintenance could go towards savings or community activities. Figures 10 and 11 present the income sources and allocations, respectively. Overall, HHs contribute most of the total income, while BEUs and IEUs contribute a significant proportion, much of which comes from the Telecoms tower which is modelled to pay NPR 26,000 (USD 220) per month. The predicted usage scenario shows that, even if HHs make some changes to their behaviour, the plant is likely to remain profitable on a monthly basis, as shown in Figure 11, and the reduced peak loads could enable additional PEUs to be connected. For this scenario, no alterations were made for the BEUs, CEUs, and IEUs as they were deemed less likely to need to reduce their payments.

The blue bars in Figure 12 show that, in scenario P1, HH Types 1 and 2 would pay the minimum of NPR 110, consuming less than $18 \mathrm{kWh}$ in the month, whereas other $\mathrm{HH}$ types would pay far more. HH Type 3, using high-power devices sparingly, would increase their monthly payments from the flat rate of NPR 110 (USD 0.93) to around NPR 200 (USD 1.69), whereas HH Type 4 and 5 payments would increase to around NPR 700 (USD 5.90) and NPR 1000 (USD 8.44), respectively, presenting the question of how willing these HHs would be to pay vastly increased sums for their electricity. Another key result is that $\mathrm{HH}$ Type 4 would generate the majority of the total income, even though it includes only $15 \%$ of the total HHs. HHs with electric cookers would pay around NPR 350 (USD 2.95), of which around NPR 275 (USD 2.32) would be for electric cooking, although these figures would vary according to cooker usage, with some HHs likely to pay up to NPR 400 (USD 3.37) per month for electric cooking alone. In the previous cooking diary study conducted in Salyan, it was found that the median monthly expenditure on LPG for cooking was USD 
3.42, even though it was mainly used as a back-up cooking fuel [22]. For wood cooking, some HHs have no associated costs because they collect firewood from their own land, while others spent around USD 8.96 per month in equivalent costs associated with time spent collecting firewood for themselves and others [22].

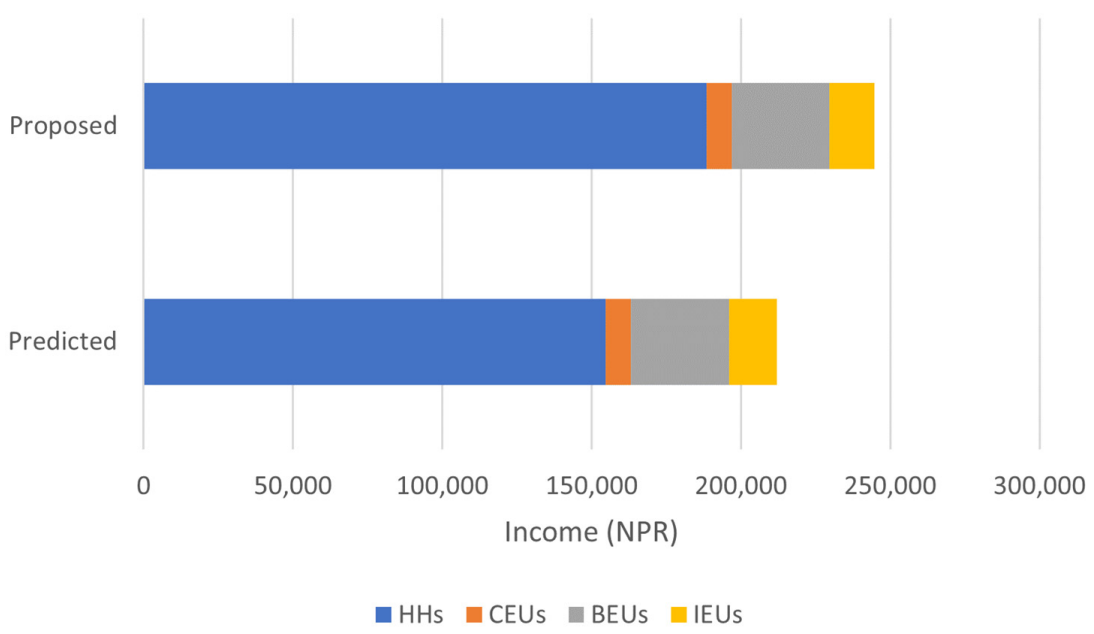

Figure 10. Income source breakdown for proposed and predicted scenarios.

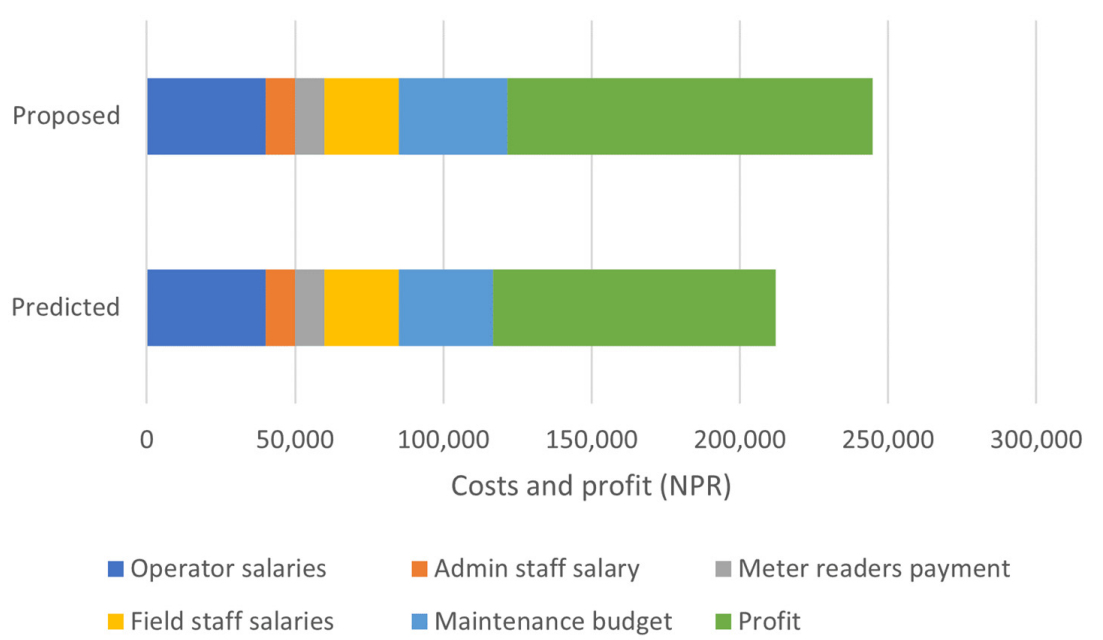

Figure 11. Costs and profit for proposed and predicted scenarios.

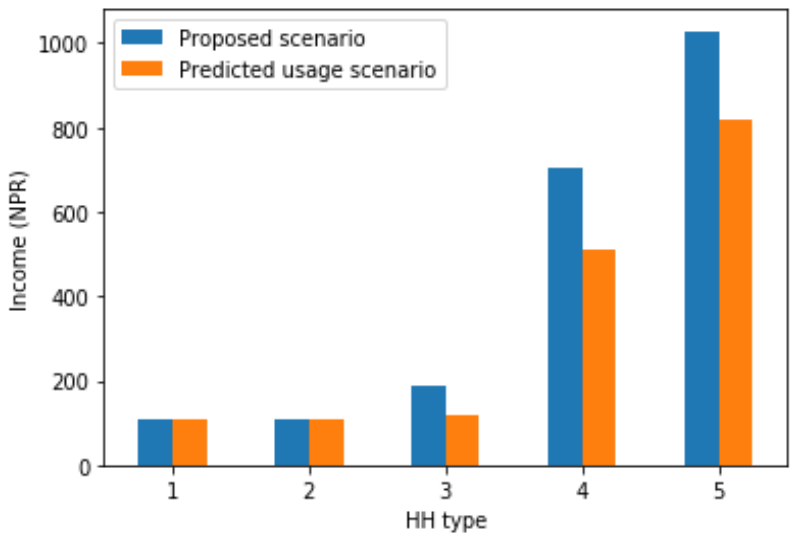

Figure 12. Single household average income across household types for proposed and predicted scenarios. 
Predicted usage on a HH level, as depicted by the orange bars in Figure 12, shows that HH Type 3 would reduce payments slightly, while Type 4 could reduce by NPR 200 (USD 1.69) but would still be required to pay NPR 500 (USD 4.22). Therefore, to reduce their monthly payments further and avoid a significant hike from the original flat rate of NPR 110 (USD 0.93), higher income HHs would have to sacrifice some of their electricity usage habits, perhaps by further reducing their usage of high-power devices and nonessential end uses such as outdoor bulbs.

The proposed tariff system is not more inclusive for lower income HHs than the flat rate system, as the minimum monthly payment is the same at NPR 110 (USD 0.93). To reduce bills for HHs who might be struggling to pay NPR 110 (USD 0.93) and using little electricity, and potentially enable HHs not currently paying due to poverty to contribute, the fixed minimum payment could be reduced from NPR 110 (USD 0.93) to, for example, NPR 50 (USD 0.42). This scenario generates an overall projected income of NPR 194,000 (USD 1640), with total HH income reducing from NPR 189,000 (USD 1590) to NPR 137,000 (USD 1160). Although clearly a substantial decrease, there would still be sufficient revenue for a high profit of around NPR 80,000 (USD 670), or NPR 50,000 (USD 420) in the predicted usage scenario. The model allows variation of key parameters to model extreme scenarios. If the increases in payments were unacceptable for consumers, the $\mathrm{HH}$ tariff could be set to NPR 50 (USD 0.42) for $18 \mathrm{kWh}$ and NPR 6 (USD 0.05) per additional unit rather than NPR 7 (USD 0.06). With this reduced tariff, and even if HHs reduced their electricity consumption according to the predicted usage scenario and 50\% of consumers did not pay regularly, a percentage closer to the current proportion not paying under the flat rate system, the plant would still generate a profit of around NPR 14,000 (USD 120) per month, and monthly payments for HH Type 4 would reduce to around NPR 400 (USD 3.37).

Figure 8 and Table 6 show that, with current consumer electricity usage patterns, the overall demand is close to maximum capacity at peak times but much lower in the afternoon. DSM measures can reduce peak loads, enabling connection of additional PEUs and appliances used during peak times, while excess energy generated in off-peak periods could also be exploited by new connections. Additional connections increase plant income, and therefore, financial sustainability. The techno-economic model can be used to plan new connections and evaluate DSM measures.

\subsection{DSM Measures and Additional End Uses}

As previously mentioned, the MHP operators are in contact with the IEU operators during peak times which reduces strain on the mini-grid. Shifting usage to off-peak times could further reduce peak loads. Figure 13 presents the resulting load profiles if a DSM measure is agreed where the mills are restricted to operation between 10 a.m. and 4 p.m. (blue line and cloud), Scenario D1. The second scenario in Figure 13, Scenario D2, builds on the measure by introducing eight extra three-phase mills and three extra single-phase mills (orange line and cloud), doubling the number of mills. Table 7 presents the key results.

Table 7. Key model outputs for Scenarios D1 and D2 with mills DSM and additional mills.

\begin{tabular}{|c|c|c|c|c|c|c|c|c|}
\hline Scenario & $\begin{array}{l}\text { Energy } \\
(\mathrm{kWh})\end{array}$ & $\begin{array}{l}\text { Income } \\
\text { (NPR) }\end{array}$ & $\begin{array}{l}\text { Costs } \\
(\text { NPR) }\end{array}$ & $\begin{array}{l}\text { Profit } \\
\text { (NPR) }\end{array}$ & $\begin{array}{l}\text { Peak Load } \\
\text { Mean (kW) }\end{array}$ & $\begin{array}{l}\text { Peak Load across } \\
\text { Month (kW) }\end{array}$ & $\begin{array}{l}\text { Peak Load Reduced } \\
\text { Variability }(\mathbf{k W})\end{array}$ & $\begin{array}{c}\text { Average } \\
\text { Load } \\
\text { Factor }(\%)\end{array}$ \\
\hline B & 37,000 & 50,000 & & & 80.7 & 108.4 & 94.6 & 60.9 \\
\hline D1 & 37,200 & 248,100 & 122,200 & 125,900 & 76.0 & 92.1 & 82.7 & 67.6 \\
\hline D2 & 37,900 & 254,000 & 123,100 & 130,900 & 76.3 & 101.8 & 88.0 & 66.8 \\
\hline
\end{tabular}




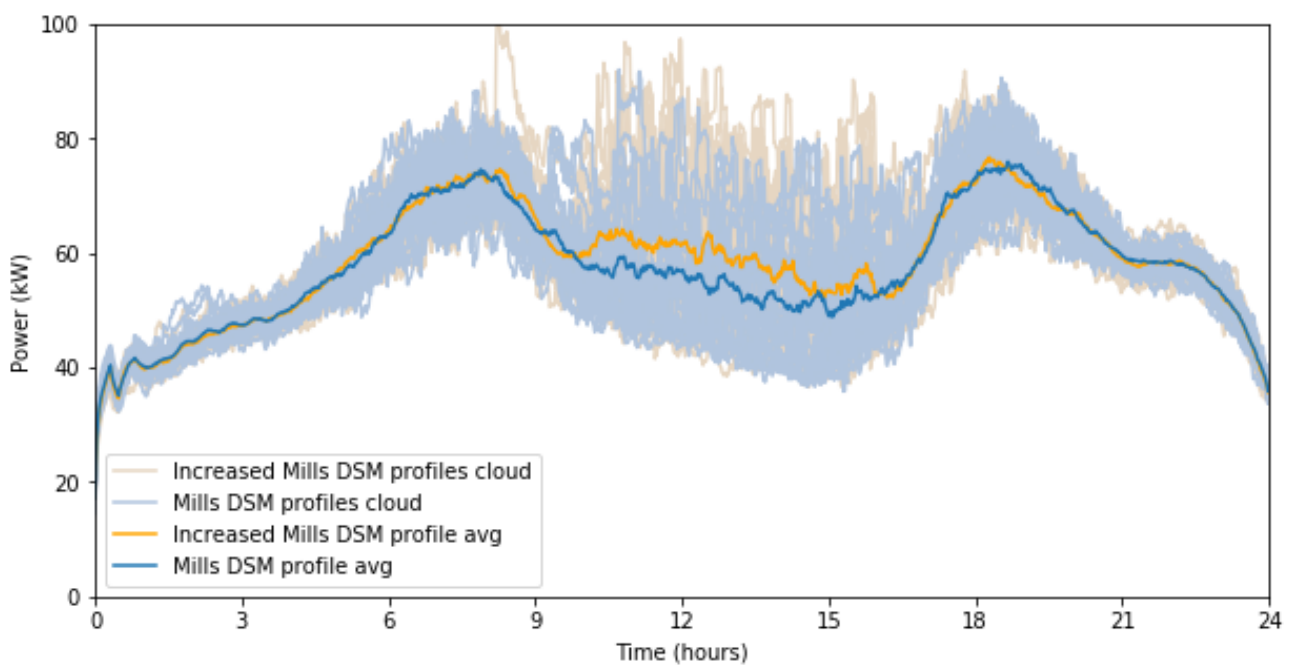

Figure 13. RAMP outputs for mill DSM measures and addition of extra mills.

The DSM agreement reduces average peak loads by around $5 \mathrm{~kW}$, while increasing the average afternoon load by around $10 \mathrm{~kW}$, to $60 \mathrm{~kW}$. Introducing additional mills increases the average afternoon load further, with the highest daily afternoon peak falling just short of $100 \mathrm{~kW}$, showing that the MHP management could confidently provide additional mill licenses to mill operators without the risk of destabilising the mini-grid in the afternoon, as long as there was adherence to the DSM agreement. Table 7 shows that the total income would increase by around NPR 6000 (USD 51), providing additional profit for the MHP.

The spare energy in the system could also be used for a wide range of other PEUs and appliances, including electric cookers. However, the proposed scenario (P1) simulation presented in Table 6 shows that, with only 10 HHs cooking on induction cookers and a further $60 \%$ of $\mathrm{HHs}$ using rice cookers and electric kettles to varying degrees, some daily profiles include peaks exceeding $100 \mathrm{~kW}$. When the variability was reduced, the maximum peak load across a month was $95 \mathrm{~kW}$. Even if the reduced variability measure is realistic, since cooking occurs during peak times, and without the reduction of peak loads, electric cooking is not scalable. It is likely that some additional HHs could use electric cookers, especially if $\mathrm{HHs}$ reduce their electricity consumption when their monthly payments increase, as in the predicted usage scenario (P2); however, on days when a high proportion of cooking windows coincide, this would increase the risk of destabilising the mini-grid.

DSM measures, for IEUs and electric cooking, could increase electric cooking scalability further. The cooking model was adapted by specification of wider cooking windows, extended by an hour in both directions, to represent the effect of a DSM measure such as an agreement that HHs only start cooking if the voltage is stable, encouraging cooking over wider periods of time, as implemented successfully in Myanmar [23]. Such an agreement is potentially feasible if $\mathrm{HH}$ meters displayed the supply voltage and training was provided, although meters would present additional costs. Figure 14 and Table 8 present Scenario D3, where the IEU DSM measure is applied and 30 electric cooking HHs are added with the cooking DSM measure implemented.

The analysis shows that DSM measures could increase electric cooking scalability significantly to a total of up to around $40 \mathrm{HHs}$ using electric cookers and generate around NPR 11,000 (USD 93) in additional income due to increased electric cooking. If many HHs in the community reduce their electricity consumption, as approximated in the predicted usage scenario (P2), further electric cookers could be introduced. However, in communities of hundreds of HHs, widespread uptake remains unfeasible without more drastic DSM measures or, more feasibly, energy storage. 


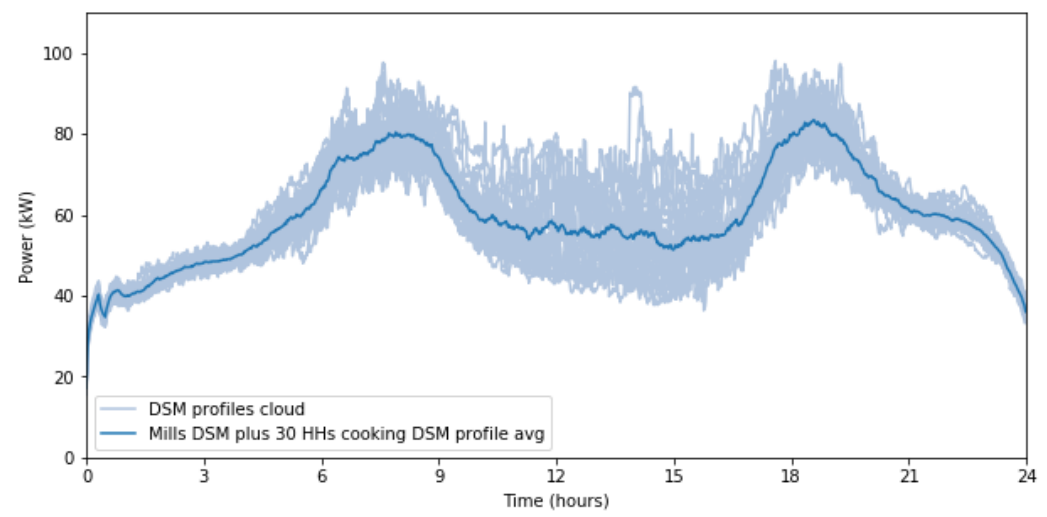

Figure 14. RAMP outputs for mill DSM plus addition of thirty electric cookers to the community.

Table 8. Key model outputs for Scenario D3 with mill DSM and additional cookers with DSM.

\begin{tabular}{ccccccccc}
\hline Scenario & $\begin{array}{c}\text { Energy } \\
\mathbf{( k W h )}\end{array}$ & $\begin{array}{c}\text { Income } \\
\mathbf{( N P R )}\end{array}$ & $\begin{array}{c}\text { Costs } \\
\mathbf{( N P R )}\end{array}$ & $\begin{array}{c}\text { Profit } \\
\mathbf{( N P R )}\end{array}$ & $\begin{array}{c}\text { Peak Load } \\
\text { Mean (kW) }\end{array}$ & $\begin{array}{c}\text { Peak Load across } \\
\text { Month (kW) }\end{array}$ & $\begin{array}{c}\text { Peak Load Reduced } \\
\text { Variability (kW) }\end{array}$ & $\begin{array}{c}\text { Average } \\
\text { Load } \\
\text { Factor (\%) }\end{array}$ \\
\hline B & 37,000 & 50,000 & & & 80.7 & 108.4 & 94.6 & 60.9 \\
\hline D3 & 38,700 & 258,400 & 123,800 & 134,600 & 83.4 & 98.1 & 89.2 & 65.0 \\
\hline
\end{tabular}

In order to simulate and specify an energy storage system in a mini-grid, the model can be used to generate cooking load profiles for different numbers of HHs, as Figure 15 shows for $100 \mathrm{HHs}$ and thirty profiles. The results show that peak loads for high numbers of $\mathrm{HHs}$ making the transition to electric cooking are much lower than the maximum coincident demand of the electric cookers, which would be around $100 \mathrm{~kW}$. Furthermore, if HHs agree to the cooking DSM measure, peak loads are reduced by approximately $40 \%$. If $\mathrm{HHs}$ use the electric cookers almost every day, simulated by increasing the frequency of use from $70 \%$ to $90 \%$, average peak loads increase to approximately 35 and $20 \mathrm{~kW}$ for normal behaviour and DSM agreement scenarios, respectively.

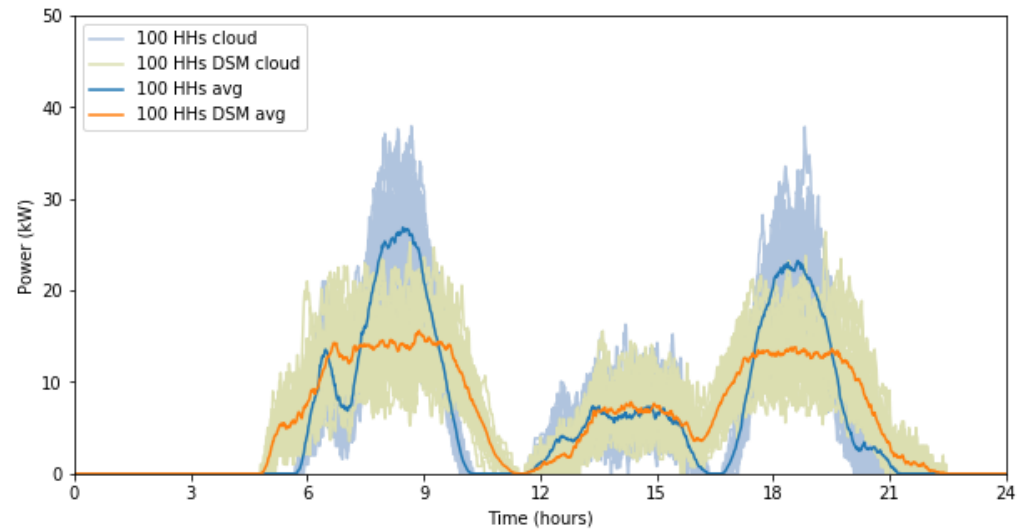

Figure 15. Electric cooking load profiles for 100 households with and without the cooking DSM measure.

\section{Discussion}

The techno-economic model provides detailed insight into the electricity demand and economics of MHPs but is not without limitations. In its current form, the RAMP demand model does not store individual user profiles within each user type, leading to average energy consumption and income for user types rather than ranges across user instances. The code could be adapted to store profiles of each user if greater detail were of interest. The model load profile outputs varied more at peak times than was observed in the 
community due to the nature of RAMP and the high number of appliances specified in the model. Assumptions on high-power appliance ownership, inability to model brownouts reducing peak loads, and MHP operators preventing coincident mill operation could contribute to the increased variability. As the economic calculations are based on total energy consumption and the average RAMP load profile agrees with measured data, key conclusions on profitability and income breakdown are unaffected, although spare power at peak times may be underestimated, and therefore is adjustable through a reduced variability measure.

Specifying $\mathrm{HH}$ user types based on survey results from a sample of only $30 \mathrm{HHs}$ carries inherent uncertainty, although detailed information can be obtained on BEUs, CEUs, and IEUs due to their lower numerosity, enabling $\mathrm{HH}$ demand to be characterised and adjusted so that community-wide outputs match measured data. Large communities without detailed bookkeeping inevitably require assumptions on the proportion of paying consumers, energy losses, and seasonality. The cooking load modelling is limited by a lack of measured load profiles for data validation. Modelling HHs with two electric cookers presented the difficulty of ensuring each cooker is used at similar times, although combining them into one appliance would be less realistic. However, with surveys conducted in only $30 \mathrm{HHs}$, a good match was obtained for the community-wide profiles to measured data, with a low NRMSE of $10 \%$. Therefore, the model can be used to generate realistic demand profiles based on limited demand data.

Using cooking diary data to inform the cooking load model specification produced similar profiles to the average diary profiles, with a reasonably low NRMSE of $18 \%$. As the diary data was examined to determine inputs to RAMP's bottom-up modelling approach such as approximate cooking windows, durations, dish frequencies, and fuel stacking, and outputs subsequently validated against cooking diary average load profiles generated from recorded cooking events, there can be confidence in the validity of the cooking load model. It could be easily adapted to other contexts with similar information on the cooking context due to its generic structure, specifying up to three dishes for each meal, and already provides a reasonable model for communities across rural Nepal where cooking practices are comparable [15]. The model scenarios were simulated for one month and did not include load evolution projections such as increasing ownership of certain appliances. RAMP is adaptable and parameters adjustable to enable easy addition of appliances, increased timescales, and sensitivity analyses to reduce uncertainties.

The model revealed that the proposed payment structure based on electricity consumption in Salyan could vastly improve the financial status of the plant, increasing monthly income by approximately $400 \%$. However, the community has a relatively high load factor as compared with other MHPs [16]. The model can be adapted to other communities with information on their electricity demand and used to simulate different payment structures to ensure a profitable and equitable structure is chosen. In Salyan, a high proportion of consumers currently do not pay the monthly flat tariff regularly. Originally, the tariff had been set according to what was deemed most acceptable for consumers, after community effort during MHP construction. It was found that many consumers were reluctant to pay due to having been involved in plant construction or currently being part of the MHP committee. Another section of consumers was unable to pay due to poverty, while others were exempt due to family member involvement in the civil war or having donated land for the MHP. The high projected profitability of the new payment structure relies on an increased proportion of paying consumers, which is deemed plausible as payments would be collected from HHs by MHP staff and consumers were generally supportive of the new system. It also assumes that consumer electricity usage patterns remain the same after electricity consumption is metered. However, running the model with a predicted usage scenario showed that the plant is likely to become profitable even if HHs reduce their electricity consumption.

Under the proposed payment structure, many HHs would be required to pay significantly more than the flat rate of NPR 110 (USD 0.93), with high income HHs likely to owe 
around NPR 500-1100 (USD 4.22-9.29) per month, depending on usage and response to the change. Previous cooking diary studies have revealed that some HHs would be willing to pay in excess of NPR 500 for electricity for cooking, but this was after the provision of induction cookers, rather than a large increase in payment for using devices already owned $[15,22]$. Therefore, it is possible that a large proportion of HHs would be reluctant to pay the increased bills. However, the model showed that if the tariff was reduced so that HH Type 4 payments were reduced to around NPR 400 (USD 3.37), and 50\% of consumers were still unwilling to pay, the system would nevertheless generate sufficient income to cover costs and make small monthly profits. Furthermore, most HHs surveyed were supportive of the new payment structure. There was an awareness that a change is required to improve the MHP financial viability. Comparing the proposed tariff system to other MHP payment structures reveals that it is cheaper than most, which are often NPR 8-10 per kWh above a certain number of units [16]. For high energy consuming HHs, such as HH Types 4 and 5, the MHP tariff is cheaper than grid electricity, which could encourage these HHs to pay the increased bills [45]. The proposed structure could also be adjusted to enable poorer HHs to pay less than the flat rate while the plant remains profitable, increasing the equitability of the system. Alongside the introduction of new tariff systems, communities could run education campaigns for consumers on MHPs and electricity consumption, encouraging appliance usage while explaining that energy saving can reduce bills and peak loads, increasing system stability.

The model showed that spare energy in the mini-grid could be used for PEUs such as additional mills or other machines, or for the introduction of electric cookers and other high-power devices, all of which would further increase economic viability. If DSM measures were employed to restrict IEUs operation to the afternoon period, reducing peak loads, it would be possible to introduce both new PEUs and electric cookers to the community. DSM measures must be specified with convenience for consumers in mind and according to cultural behaviour patterns to ensure effectiveness. The model showed that the number of mills could be doubled if usage were restricted to $10 \mathrm{a} . \mathrm{m}$. to 4 p.m. This measure would require monitoring to identify whether there were windows of concentrated usage within the off-peak period and, if required, the agreement could be extended to restrict usage to different windows for different groups of mill operators, and the model used to approximate the resulting load profiles. As is currently practiced in Salyan, MHP operators could communicate with mill operators to prevent high levels of coincident mill operation by monitoring mini-grid status. The cooking DSM measure, while increasing electric cooking scalability, could cause inconvenience and necessitate excessive behavioural change in terms of cooking times, and would require voltage meters. Even with DSM measures, in MHP communities of hundreds of HHs, electric cooking scalability is very limited. The model developed in this paper can be used to generate realistic community-wide demand profiles including cooking, enabling simulation and specification of energy storage systems which could increase the uptake of electric cooking.

\section{Conclusions}

A techno-economic model based on RAMP stochastic load model was developed for Salyan, a micro-hydropower community in rural Nepal, generating electricity demand profiles and economic viability indicators. Previous studies have assessed the sustainability of MHP communities and characterised their electricity demand, but this is the first to create a detailed, adaptable model which approximates the load breakdown of households and PEUs, estimates energy consumption and plant economics, and enables load planning. The model showed that a new, proposed payment structure based on electricity consumption rather than a flat rate could increase plant income by $400 \%$, dramatically improving the system financial sustainability. As the load factor in Salyan is relatively high, other communities may not generate similar profits with the same payment structure. The model can be used to assess and determine profitable, equitable payment structures for off-grid communities in Nepal and elsewhere, which meet the needs of the people and 
the plant, ensuring sufficient income while remaining fair and inclusive for consumers. It would be especially useful for communities wanting to switch to a tariff system based on consumption or generating insufficient income. A close adherence to measured load data was obtained with low detail input data from surveys with a community representative and a sample of thirty households, showing that the model can be constructed without comprehensive input data.

The model can be used to plan new connections such as industrial machines and electric cookers and to evaluate DSM measures that utilise the spare energy in mini-grids. Overall, it was found that the number of mills in the community could be doubled, up to 40 households provided with electric cookers if DSM measures were introduced, or both if the measures are respected. The paper also contributes a validated electric cooking load model for Nepali cooking, adaptable to different cookers and contexts, which can be used to approximate peak cooking loads, showing that they are significantly lower than the maximum possible coincident demand. The resulting load profiles could be used for realistic sizing of energy storage systems to enable increased uptake of electric cooking. Future work should include surveys in the case study community on household willingness to pay increased bills and data collection on their electricity consumption and resulting payments after the new payment structure is introduced. The techno-economic model could be updated to assess plant economics, inform load planning decisions, and simulate DSM measures. Energy storage modelling could be incorporated to enable specification and realisation of storage systems and trial projects to enable increased uptake of electric cooking in MHP communities.

Author Contributions: Conceptualization, W.C., S.P., P.B., J.B., S.W. and P.H.; Data curation, W.C.; Formal analysis, W.C.; Funding acquisition, W.C., S.P., S.W. and B.G.; Investigation, W.C., S.P. and P.B.; Methodology, W.C., S.P., P.B., J.B. and S.W.; Project administration, W.C., S.P., P.B., S.W. and B.G.; Software, W.C.; Supervision, S.W. and B.G.; Validation, S.W.; Visualization, W.C.; Writing—original draft, W.C.; Writing-review \& editing, W.C., S.P., P.B., J.B., S.W., B.G. and P.H. All authors have read and agreed to the published version of the manuscript.

Funding: The cooking diary studies were funded by Modern Energy Cooking Services (MECS) TRIID and ECO Challenge Funds. The MECS programme is funded by UK Aid (GB-GOV-1-300123). The research was also funded by a studentship of Will Clements from the Engineering and Physical Sciences Research Council (EP/R513179/1).

Institutional Review Board Statement: All subjects gave their informed consent for inclusion before they participated in the study. The study was conducted in accordance with the Declaration of Helsinki, and the protocol was approved by the Ethics Committee of the University of Bristol (Project identification code 115885).

Data Availability Statement: Data are available at the University of Bristol data repository, data.bris, at https:/ / doi.org/10.5523/bris.lpsryevp8vxk2royoexrh2hvw, accessed on 12 July 2021.

Acknowledgments: The field work was implemented by the People Energy and Environment Development Association and Kathmandu Alternative Power and Energy Group. The authors would like to thank the developers of RAMP for their model, in particular, Francesco Lombardi, who provided valuable advice and technical support on the use of RAMP.

Conflicts of Interest: The authors declare no conflict of interest. The funders had no role in the design of the study; in the collection, analyses or interpretation of data; in the writing of the manuscript; or in the decision to publish the results.

\section{References}

1. United Nations. Sustainable Development Goals Knowledge Platform: Sustainable Development Goals. Available online: https: / / sustainabledevelopment.un.org/?menu=1300 (accessed on 17 April 2019).

2. Nepal Micro Hydropower Development Association. MH in Nepal. Available online: https://microhydro.org.np/mh-in-nepal/ (accessed on 6 October 2020).

3. Butchers, J.; Williamson, S.; Booker, J.; Tran, A.; Karki, P.B.; Gautam, B. Understanding sustainable operation of micro-hydropower: A field study in Nepal. Energy Sustain. Dev. 2020, 57, 12-21. [CrossRef] 
4. Thapa, R.B.; Upreti, B.R.; Devkota, D.; Pokharel, G.R. Validating technical performance of micro-hydropower plants in Nepal. J. Agric. For. Univ. 2019, 3, 25-36.

5. Sovacool, B.K.; Bambawale, M.J.; Gippner, O.; Dhakal, S. Electrification in the Mountain Kingdom: The implications of the Nepal Power Development Project (NPDP). Energy Sustain. Dev. 2011, 15, 254-265. [CrossRef]

6. Practical Action. Poor People's Energy Outlook 2018; Practical Action: Rugby, UK, 2018.

7. Nepal Ministry of Finance. Economic Survey 2017/18; Ministry of Finance: Kathmandu, Nepal, 2018.

8. Nepal Central Bureau of Statistics. Annual Household Survey 2014/15; Central Bureau of Statistics: Kathmandu, Nepal, 2016; ISBN 9789937012782.

9. Killer in the Kitchen-Practical Action. Available online: https://practicalaction.org/our-work/projects/killer-in-the-kitchen/ (accessed on 19 March 2020).

10. Butchers, J.; Williamson, S.; Booker, J.; Tran, A.; Gautam, B.; Karki, P.B. A Study of Technical, Economic and Social Factors Affecting Micro-Hydropower Plants in Nepal. In Proceedings of the 2018 IEEE Global Humanitarian Technology Conference (GHTC), San Jose, CA, USA, 18-21 October 2018; pp. 446-453. [CrossRef]

11. Brüderle, A.; Attigah, B.; Bodenbender, M. Productive Use of Energy_PRODUSE A Manual for Electrification Practitioners; European Union Energy Initiative Partnership Dialogue Facility, GIZ: Eschborn, Germany, 2011.

12. Bhandari, R.; Saptalena, L.G.; Kusch, W. Sustainability assessment of a micro hydropower plant in Nepal. Energy. Sustain. Soc. 2018, 8, 3. [CrossRef]

13. Yadoo, A.; Cruickshank, H. The role for low carbon electrification technologies in poverty reduction and climate change strategies: A focus on renewable energy mini-grids with case studies in Nepal, Peru and Kenya. Energy Policy 2012, 42, 591-602. [CrossRef]

14. Silwal, K.; Freere, P.; Pandit, S.; Clements, W. Very Weak Isolated Microhydro Grid Effects on Electric Cooking in Nepal. In Proceedings of the 2020 International Conference on Electrical Engineering and Control Technologies (CEECT), Melbourne, Australia, 10-13 December 2020; pp. 1-6.

15. Clements, W.; Silwal, K.; Pandit, S.; Leary, J.; Gautam, B.; Williamson, S.; Tran, A.; Harper, P. Unlocking electric cooking on Nepali micro-hydropower mini-grids. Energy Sustain. Dev. 2020, 57, 119-131. [CrossRef]

16. Winrock International for Agricultural Development. Baseline Report of Micro Hydro Plants (MHP) Selected under Sharing Learning across Projects: Operating MHPs as Commercially Viable Enterprises; Wuppertal Institute for Climate, Environment and Energy: Wuppertal, Germany, 2017.

17. Quetchenbach, T.G.; Harper, M.J.; Robinson, J., IV; Hervin, K.K.; Chase, N.A.; Dorji, C.; Jacobson, A.E. The GridShare solution: A smart grid approach to improve service provision on a renewable energy mini-grid in Bhutan. Environ. Res. Lett. 2013, 8, 014018. [CrossRef]

18. Williamson, S.J.; David Lubitz, W.; Williams, A.A.; Booker, J.D.; Butchers, J.P. Challenges Facing the Implementation of PicoHydropower Technologies. J. Sustain. Res. 2019, 2, e200003. [CrossRef]

19. Livelihood Improvement through Inclusive Finance and Technology Private Limited (LIIFT Nepal). Establishing Sustainable Model for Financing Community-Based Micro-Hydro Projects through Local Financial Institutions; Alternative Energy Promotion Centre, Renewable Energy for Rural Livelihood Programme: Kathmandu, Nepal, 2017.

20. Kim, E.; Karky, B.S. Water resources use in the Annapurna Conservation Area: Case study of micro-hydropower management in Sikles and Chhomrong. In Proceedings of the Case Study on Mountain Infrastructure: Access, Communications, Energy, Mountain Forum E-Consultation for the UNEP/Bishkek Global Mountain Summi, Bishkek, Kyrgyzstan, 29 October-1 November 2002.

21. Pokharel, G.R.; Chhetri, A.B.; Khan, M.I.; Islam, M.R. Decentralized micro-hydro energy systems in Nepal: En route to sustainable energy development. Energy Sources Part B Econ. Plan. Policy 2008, 3, 144-154. [CrossRef]

22. Gautam, B.; Pandit, S.; Clements, W.; Williamson, S.; Silwal, K. Assessing Electric Cooking Potential in Micro Hydropower Microgrids in Nepal. 2020. Available online: https://mecs.org.uk/wp-content/uploads/2020/12/MECS-TRIID-PEEDA_ updated-Report.pdf (accessed on 12 July 2021).

23. Leary, J.; Hlaing, W.; Myint, A.; Win, P.; Phyu, M.; Moe, E.T.; Scott, N.; Batchelor, S.; Vaghela, D. Opportunities \& Challenges for eCook Myanmar. 2019. Available online: https://www.mecs.org.uk/wp-content/uploads/2020/12/eCook-Myanmar-CountryWorking-Paper-29-10-19-COMPRESSED.pdf (accessed on 12 July 2021).

24. Butchers, J.; Williamson, S.; Booker, J. Micro-Hydropower in Nepal: Analysing the Project Process to Understand Drivers that Strengthen and Weaken Sustainability. Sustainability 2021, 13, 1582. [CrossRef]

25. Müller, M.F.; Thompson, S.E.; Gadgil, A.J. Estimating the price (in)elasticity of off-grid electricity demand. Dev. Eng. 2018, 3, 12-22. [CrossRef]

26. Casillas, C.E.; Kammen, D.M. The delivery of low-cost, low-carbon rural energy services. Energy Policy 2011, $39,4520-4528$. [CrossRef]

27. Lombardi, F.; Balderrama, S.; Quoilin, S.; Colombo, E. Generating high-resolution multi-energy load profiles for remote areas with an open-source stochastic model. Energy 2019, 177, 433-444. [CrossRef]

28. Richardson, I.; Thomson, M.; Infield, D.; Clifford, C. Domestic electricity use: A high-resolution energy demand model. Energy Build. 2010, 42, 1878-1887. [CrossRef]

29. Widén, J.; Wäckelgård, E. A high-resolution stochastic model of domestic activity patterns and electricity demand. Appl. Energy 2010, 87, 1880-1892. [CrossRef] 
30. Good, N.; Zhang, L.; Navarro-Espinosa, A.; Mancarella, P. High resolution modelling of multi-energy domestic demand profiles. Appl. Energy 2015, 137, 193-210. [CrossRef]

31. Fischer, D.; Härtl, A.; Wille-Haussmann, B. Model for electric load profiles with high time resolution for German households. Energy Build. 2015, 92, 170-179. [CrossRef]

32. Tsagarakis, G.; Collin, A.J.; Kiprakis, A.E. Modelling the electrical loads of UK residential energy users. In Proceedings of the 2012 47th International Universities Power Engineering Conference (UPEC), Uxbridge, UK, $4-7$ September 2012; pp. 1-6. [CrossRef]

33. Marszal-Pomianowska, A.; Heiselberg, P.; Kalyanova Larsen, O. Household electricity demand profiles-A high-resolution load model to facilitate modelling of energy flexible buildings. Energy 2016, 103, 487-501. [CrossRef]

34. Boait, P.; Gammon, R.; Advani, V.; Wade, N.; Greenwood, D.; Davison, P. ESCoBox: A set of tools for mini-grid sustainability in the developing world. Sustainability 2017, 9, 738. [CrossRef]

35. Mandelli, S.; Merlo, M.; Colombo, E. Novel procedure to formulate load profiles for off-grid rural areas. Energy Sustain. Dev. 2016, 31, 130-142. [CrossRef]

36. Balderrama, S.; Lombardi, F.; Riva, F.; Canedo, W.; Colombo, E.; Quoilin, S. A two-stage linear programming optimization framework for isolated hybrid microgrids in a rural context: The case study of the "El Espino" community. Energy 2019, 188, 116073. [CrossRef]

37. Stevanato, N.; Lombardi, F.; Guidicini, G.; Rinaldi, L.; Balderrama, S.L.; Pavičević, M.; Quoilin, S.; Colombo, E. Long-term sizing of rural microgrids: Accounting for load evolution through multi-step investment plan and stochastic optimization. Energy Sustain. Dev. 2020, 58, 16-29. [CrossRef]

38. Stevanato, N.; Rinaldi, L.; Pistolese, S.; Balderrama, S.; Quoilin, S.; Colombo, E. Modeling of a Village-Scale Multi-Energy System for the Integrated Supply of Electric and Thermal Energy. Appl. Sci. 2020, 10, 7445. [CrossRef]

39. Lombardi, F.; Rocco, M.V.; Colombo, E. A multi-layer energy modelling methodology to assess the impact of heat-electricity integration strategies: The case of the residential cooking sector in Italy. Energy 2019, 170, 1249-1260. [CrossRef]

40. Lombardi, F.; Riva, F.; Sacchi, M.; Colombo, E. Enabling combined access to electricity and clean cooking with PV-microgrids: New evidences from a high-resolution model of cooking loads. Energy Sustain. Dev. 2019, 49, 78-88. [CrossRef]

41. Modern Energy Cooking Services (MECS). MECS-ECO Challenge Fund-Modern Energy Cooking Services. Available online: https:/ / mecs.org.uk/challenge-fund/past-funds/mecs-eco-challenge-fund/ (accessed on 14 May 2021).

42. Chan, J.; Lubitz, W. Electronic load controller (ELC) design and simulation for remote rural communities: A powerhouse ELC compatible with household distributed-ELCs in Nepal. In Proceedings of the 2016 IEEE Global Humanitarian Technology Conference (GHTC), Seattle, WA, USA, 13-16 October 2016; pp. 360-367. [CrossRef]

43. United Nations Nepal. Nepal Administrative Unit-Province 1 Map_UN Nepal Information Platform. Available online: https: / / un.org.np/index.php/map/nepal-administrative-unit-province-1-map (accessed on 14 May 2021).

44. Kitson, J.; Williamson, S.J.; Harper, P.W.; McMahon, C.A.; Rosenberg, G.; Tierney, M.J.; Bell, K.; Gautam, B. Modelling of an expandable, reconfigurable, renewable DC microgrid for off-grid communities. Energy 2018, 160, 142-153. [CrossRef]

45. Nepal Electricity Authority (NEA). Consumer Tariff Data Grid Electricity. Available online: https://www.nea.org.np/admin/ assets / uploads/Consumer_Tarrif_data.pdf (accessed on 12 July 2021). 